\title{
Perioperative and postoperative course of cytokines and the metabolic activity of neutrophils in human cardiac operations and heart transplantation
}

\author{
Lukáš Kubala, $P h D^{a}$ \\ Milan Číž, PhD \\ Jan Vondráček, $\mathrm{PhD}^{\mathrm{a}}$ \\ Jan Černý, MD, PhD \\ Petr Němec, $M D^{\mathrm{b}}$ \\ Pavel Studeník, MD ${ }^{b}$ \\ Hana Čižová, $\mathrm{PhD}^{\mathrm{a}}$ \\ Antonín Lojek, $\mathrm{PhD}^{\mathrm{a}}$
}

See related editorial on page 1071.

From the Institute of Biophysics, ${ }^{a}$ Královopolská, and the Centre of Cardiovascular and Transplantation Surgery, ${ }^{\mathrm{b}}$ Pekarská, Brno, Czech Republic.

This study was elaborated in the frame of research plan of the Academy of Sciences of the Czech Republic No. Z 5004920 and was supported by grants of the Grant Agency of Czech Republic No. 524/01/ 1219 and No. 524/00/1223.

Received for publication Sept 27, 2001; revisions requested Jan 19, 2002; revisions received April 11, 2002; accepted for publication April 18, 2002.

Address for reprints: Lukáš Kubala, PhD, Institute of Biophysics, Academy of Sciences of the Czech Republic, Královopolská 135, Brno, CZ 612 65, Czech Republic (E-mail: kubalal@ibp.cz).

J Thorac Cardiovasc Surg 2002;124:1122-9

Copyright () 2002 by The American Association for Thoracic Surgery

0022-5223/2002 $\$ 35.00+0 \quad \mathbf{1 2 / 1 / 1 2 5 8 1 4}$

doi: $10.1067 / \mathrm{mtc} .2002 .125814$
Objectives: The purpose of this study was to compare systemic inflammatory responses after heart transplantation and nontransplant cardiac operations, both involving cardiopulmonary bypass with a focus on the role of polymorphonuclear leukocytes.

Methods: Lipid peroxidation, blood phagocyte radical production, and interleukin 6, 8 , and 10 plasma concentrations during surgical intervention and on the first and seventh postoperative days were evaluated in patients undergoing heart transplantation $(\mathrm{n}=24)$ and in patients not undergoing transplantation $(\mathrm{n}=30)$.

Results: Levels of interleukin 6, 8, and 10 increased in both groups of patients during early reperfusion. They normalized within the first postoperative day in the transplant group, whereas the nontransplant group's interleukin 6 and 8 levels remained increased on the seventh day after the operation. Interleukin 10 plasma levels were higher in the heart transplant group during reperfusion. Lipid peroxidation was increased after the operation in both groups of patients. Phagocyte activity was enhanced at reperfusion and at all other sampling times only in the nontransplant group. On the other hand, phagocyte activity oscillated around the preoperative level during heart transplantation, or it was even decreased.

Conclusion: Both cardiac operations involving heart transplantation and those without transplantation are associated with increased oxidative stress and an enhanced production of proinflammatory and anti-inflammatory cytokines. Differences in interleukin 10 production and phagocyte activity could be caused mainly by the immunosuppressive therapy in heart transplant operations.

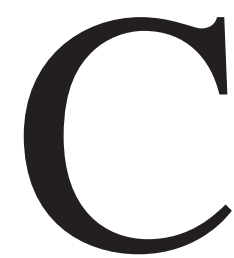

ardiac surgery involving cardiopulmonary bypass (CPB) is associated with systemic inflammatory response, which is considered to affect the clinical outcome of operations and could be caused by several factors, including the exposure of blood to the extracorporeal circuit, postischemic reperfusion of the heart and lungs, and surgical trauma. ${ }^{1-3}$ Mediators released during the inflammatory response promote polymorphonuclear cell adhesion to the endothelial surface and evoke their infiltration in tissues and the release of reactive oxygen species (ROS) and enzymes. ${ }^{4,5}$ There are some important differences between the early phase of heart transplantation (HTx) and nontransplant cardiac operations (non-HTx). Organ 
TABLE 1. Clinical data on the HTx and non-HTx groups

\begin{tabular}{lcc}
\hline & HTx group & Non-HTx group \\
\hline Age (y) & $46.0(44.5 ; 54.5)$ & $63.0^{*}(55.0 ; 72.0)$ \\
Sex ratio (male/female) & $21: 3$ & $15: 15$ \\
CPB time (min) & $103.0(88.5 ; 125.0)$ & $66.5 \dagger(58.0 ; 85.0)$ \\
Ischemic time (min) & $164(147 ; 202)$ & $36^{*}(31 ; 52)$ \\
\hline
\end{tabular}

Data are expressed as medians and lower and upper quartiles, except the sex ratio, which is expressed as the number of patients. Asterisks mark significant differences between the HTx and non-HTx groups (MannWhitney $U$ test; $\left.{ }^{*} P<.001 ; \dagger .001 \leq P<.01\right)$. The term ischemic time denotes the graft ischemic time in the HTx group or the aortic crossclamping time in the non-HTx group.

grafts are subjected to periods of both cold and warm ischemia during storage and implantation, which extend the duration of heart ischemia. ${ }^{6}$

Cytokines, such as interleukin 6 (IL-6) and IL-8, which are known to be produced during cardiac operations, belong to potent proinflammatory mediators with a wide range of biologic activities. ${ }^{7,8}$ Their effects on neutrophils could exacerbate both local and remote tissue damage. ${ }^{5,9}$ The extent of their increase can be correlated with the severity of the operation, and both cytokines have been suggested as markers with prognostic value for the outcome of the operation. $3,6,7,10,11$

Conversely, the anti-inflammatory cytokine IL-10, which is also produced during human organ transplantation, has been reported to downregulate the activity and release of proinflammatory cytokines, including IL-6 and IL-8. ${ }^{12}$ Through these mechanisms, IL-10 can contribute to the downregulation of the postreperfusion injury development and systemic inflammatory response. ${ }^{8}$

The aim of this study was to better clarify interrelationships among the plasma levels of IL-6, IL-8, and IL-10; blood phagocyte ROS production; and oxidative stressinduced damage in patients undergoing HTx and non-HTx. The parameters from both groups of patients were compared.

\section{Materials and Methods}

\section{Patients}

The study was approved by the local ethics committee, and verbal informed consent was obtained from each subject. Only patients undergoing HTx or non-HTx without complications during the first postoperative week were selected, and their data were evaluated. Indications for HTx were dilated cardiomyopathy $(\mathrm{n}=18)$ and ischemic heart disease $(n=6)$. Indications for non-HTx were ischemic heart disease $(n=19)$, aortic valve replacement $(n=5)$, and mitral valve replacement $(n=6)$. The groups are described in Table 1. Cold crystalloid cardioplegia (St Thomas Hospital solution) was used for cardiac preservation in both groups of patients. In the HTx group the heart was perfused with $1000 \mathrm{~mL}$ of cardioplegic solution before donor cardiectomy. In the non-HTx group, the total volume of cardiplegic solution used was $1300 \mathrm{~mL}$ (median) with lower and upper quartiles of 1000 and $1500 \mathrm{~mL}$, respectively, depending on the crossclamping time. The postoperative care was similar in both groups of patients, except for the immunosuppressive therapy.

\section{Immunosuppressive Protocol in the HTx Group}

Generally, the immunosuppressive regimen consisted of azathioprine $\left(1.5 \mathrm{mg} / \mathrm{kg}\right.$ before transplantation and $3 \mathrm{mg} \cdot \mathrm{kg}^{-1} \cdot \mathrm{d}^{-1}$ on days 1-2 after the operation reduced to $2 \mathrm{mg} \cdot \mathrm{kg}^{-1} \cdot \mathrm{d}^{-1}$ on days $3-7$ ), methylprednisolone (500 $\mathrm{mg}$ before the operation and then $300 \mathrm{mg} / \mathrm{d}$ for the first 3 postoperative days), cyclosporine A (INN: ciclosporin $\mathrm{A} ; 0.5 \mathrm{mg} \cdot \mathrm{kg}^{-1} \cdot \mathrm{d}^{-1}$ on days $1-2$ after the operation and then maintained at $600-800 \mathrm{ng} / \mathrm{mL}$ blood on days 3-7), and prednisone $\left(0.6 \mathrm{mg} \cdot \mathrm{kg}^{-1} \cdot \mathrm{d}^{-1}\right.$ on days $\left.3-7\right)$.

\section{Sampling and Determination of Cytokine and Lipid Peroxide Levels}

Heparinized peripheral blood samples were taken from the patients before the operation; at the time of reperfusion; 30 minutes, 4 hours, and 24 hours after reperfusion; and on the seventh day after the operation. Total and differential counts, hematocrit levels, and the oxidative burst of phagocytes were determined immediately. Plasma samples for cytokine and lipid peroxidation detection were frozen and stored at $-30^{\circ} \mathrm{C}$. Plasma levels of cytokines were determined by using commercially available enzyme-linked immunosorbent assay kits from R\&D Systems (Quantikine IL-6, IL-8, and IL-10). The detection limit for cytokine levels was 5 $\mathrm{pg} / \mathrm{mL}$. The concentration of thiobarbituric acid reactive substances, which is the index of lipid peroxidation, was determined spectrophotometrically. ${ }^{13}$

\section{Oxidative Burst of Phagocytes}

Luminol-enhanced chemiluminescence of whole-blood phagocytes was measured with a Luminometer LM-01T (Immunotech), as described previously. ${ }^{4}$ The principle of the method is based on luminol interaction with the phagocyte-derived free radicals, which results in large measurable amounts of light. Spontaneous and opsonized zymosan particle (OZP)-activated chemiluminescence was measured for 60 minutes at $37^{\circ} \mathrm{C}$. The integral value of the chemiluminescence reaction, which represents the total ROS production by the blood phagocytes, was corrected for $10^{3}$ neutrophil granulocytes.

\section{Statistical Analysis}

Data were not normally distributed, and therefore nonparametric statistical methods were used (Statistica for Windows 5.0, StatSoft, Inc). Data are expressed as medians and lower and upper quartiles. At each time point, the Mann-Whitney $U$ test was applied to compare the groups of patients. The Wilcoxon test was used for the inspection of differences between preoperative values and different time points within each group. Interrelationships among variables were assessed by using the Pearson correlation test.

\section{Results}

Time Profiles of Cytokine Levels

Plasma levels of IL-6, IL-8, and IL-10 were increased in patients undergoing HTx at the time of reperfusion, with 


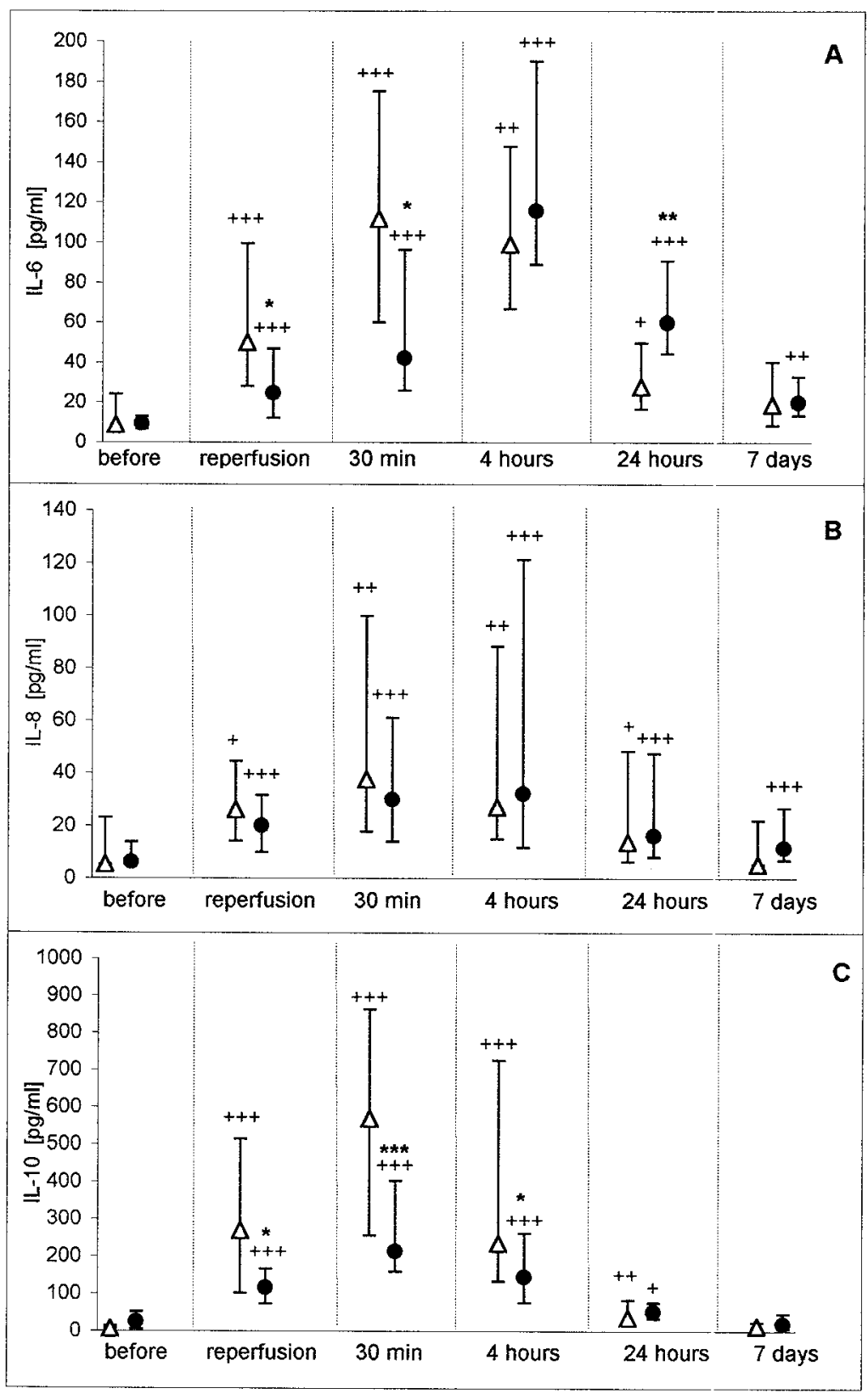

Figure 1. Time profiles of IL-6 (A), IL-8 (B), and IL-10 (C) plasma levels. The ordinate represents actual values in both the HTx (open triangles) and non-HTx (filled circles) groups at different sampling times: before the operation; at the time of reperfusion; 30 minutes, 4 hours, and 24 hours after reperfusion; and 7 days after operation. Asterisks mark the sampling times when the values of a specified parameter differed significantly between the HTx $(n=24)$ and non-HTx $\left(\mathrm{n}=30\right.$ ) groups (Mann-Whitney $U$ test; $\left.{ }^{* * *} \boldsymbol{P}<.001 ;{ }^{* *} .001<P<.01 ;{ }^{*} .01<P<.05\right)$. Crosses mark the sampling times when the values of a specified parameter differed significantly from the preoperative values (Wilcoxon matched paired test; $+++P<.001 ;++.001<P<.01 ;+.01<P<.05$ ).

further remarkable increases 30 minutes after reperfusion (Figure 1). Whenever a stimulation of IL release occurred, it decreased sharply 24 hours after reperfusion and returned to preoperative levels on the seventh day after the operation. All the observed cytokines were increased in a similar pattern in the non-HTx group. However, IL-6 and IL-8 plasma levels reached their peak values later (4 hour after reperfusion) and did not return to the preoperative levels on the seventh day after the operation in the non-HTx group. The plasma levels of IL-6 were higher in the HTx group 
than in the non-HTx group in the early phase of reperfusion (up to 30 minutes after reperfusion), whereas IL-6 levels were higher in the non-HTx group 24 hours after reperfusion (Figure 1,A). The plasma levels of IL-8 did not remarkably differ between the HTx and non-HTx groups (Figure 1, B). IL-10 plasma levels were higher in the HTx group than in the non-HTx group from reperfusion to 4 hours after reperfusion (Figure 1,C).

\section{Time Course of Changes in Total and Differential Counts of Leukocytes}

Total leukocyte counts were increased in both groups of patients from reperfusion to the seventh day after the operation when compared with the preoperative levels (Figure 2, A). Leukocyte numbers were higher in the HTx group at all sampling intervals.

The sharp increase in the total number of leukocytes was associated with a relative increase in neutrophils (mainly of not fully maturated neutrophils; Figure 2, B). They increased remarkably at the time of reperfusion and remained higher up to 24 hours after reperfusion in both groups of patients. The percentage of segmented-maturated neutrophils was increased from the time of reperfusion to 24 hours after reperfusion only in the non-HTx group (Figure 2, C). In the HTx group the segmented neutrophils were increased only 24 hours after reperfusion and on the seventh day after the operation.

\section{Time Profiles of Spontaneous and Activated Chemiluminescence}

Spontaneous chemiluminescence was decreased during reperfusion and 30 minutes after reperfusion in the HTx group when compared with the preoperative level (Figure 3, A). After that, the chemiluminescence activity oscillated around the preoperative value. On the other hand, spontaneous chemiluminescence was increased when compared with its preoperative levels in the non-HTx group at all sampling intervals. OZP-activated chemiluminescence was not increased to greater than the preoperative level in the HTx group at any of the sampling intervals (Figure 3, B). However, in the non-HTx group the activated chemiluminescence was increased at all sampling intervals compared with the preoperative level. Both spontaneous and OZPactivated chemiluminescence were higher in the non-HTx group than in the HTx group at all perioperative and postoperative sampling times.

\section{Time Course of Malondialdehyde Concentration}

Plasma levels of thiobarbituric acid reactive substances were increased 30 minutes and 4 hours after reperfusion in both groups of patients (Table 2).

\section{Correlation Among Monitored Parameters}

Correlation analysis detected positive correlation between IL-6 and IL-8 in samples from both the HTx and non-HTx groups at the time of reperfusion and 30 minutes, 4 hours, and 24 hours after reperfusion (Table 3 ). No other consistent correlations were found among the evaluated parameters.

\section{Discussion}

Cardiac operations involving CPB is associated with a systemic inflammatory response, which is an extremely complex phenomenon related to the release of various cytokines. ${ }^{1}$ Their release can be triggered by many factors, such as surgical procedure, duration of the ischemia and reperfusion in the heart, exposure of blood to the extracorporeal circuit, or release of endotoxin. ${ }^{6}$ The release of cytokines is important because such a release is implicated in the development of postoperative complications. . $^{3,7,8,11,14}$ A better understanding of cytokine responses might lead to new therapeutic implications.

The increase in the plasma levels of IL-6, IL-8, and IL-10 within the early phase of reperfusion in patients undergoing cardiac operations involving CPB has already been described in many studies. ${ }^{3,5,6,9-12,15-17}$ However, only several studies have evaluated these parameters in patients undergoing HTx ${ }^{18,19}$ or compared both groups of patients. ${ }^{6}$ The cytokine levels mostly normalized within the first or second postoperative days in both HTx and cardiac operations. These results were confirmed in our study, in which IL-6, IL-8, and IL-10 kinetics were measured during and after HTx and non-HTx operations involving CPB. Heart storage and longer duration of acute ischemia starting from aortic crossclamping are important factors differentiating the early phase of HTx from non-HTx. ${ }^{6}$ Therefore a stronger inflammatory response might be expected during HTx. On the other hand, the HTx group received the immunosuppressive drugs azathioprine and methylprednisolone during the operation. It is well documented that early steroid administration before $\mathrm{CPB}$ can reduce the inflammatory response and enhance the release of IL-10.8,10,18,20

We found IL-6 and IL-8 plasma concentrations to be approximately on the same level in both groups of patients. On the other hand, the plasma concentration of IL-10 was remarkably higher in the HTx group. Therefore we suggest that immunosuppressive therapy prevented the expected more intensive release of IL- 6 and IL- 8 in these patients. To the contrary, the extended IL-10 release in the HTx group could also be caused by both immunosuppressive therapy and a more profound ischemic period. The absence of immunosuppressive therapy in the non-HTx group might be a reason for the higher IL- 6 and IL- 8 concentrations found in these patients on day 7 after the operation. Contrary to our results, Wan and colleagues ${ }^{6}$ found higher IL-8 and IL-6 release in patients having undergone HTx than in patients after non-HTx. IL-10 was at the same level in both groups. In our study the cytokine levels and blood phagocyte ROS production had relatively low variability before surgical treatment and did not differ significantly between the 2 


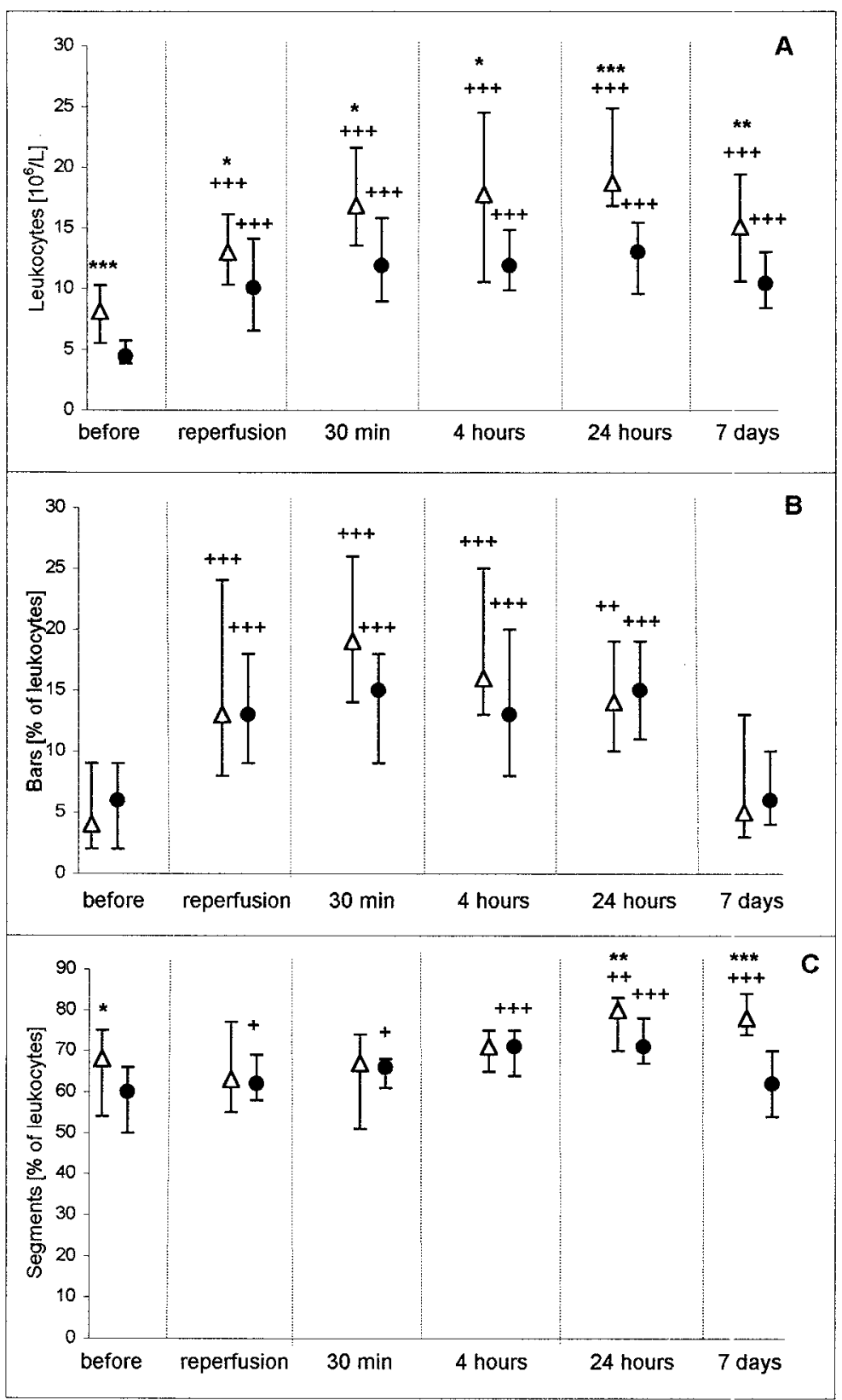

Figure 2. Time profiles of leukocyte counts. Panel A shows the total leukocyte counts corrected for hemodilution. Panel B shows the relative counts of not fully maturated neutrophils (bars), and panel C shows the relative counts of fully maturated neutrophils (segments). The ordinate represents actual values in both the HTx (open triangles) and non-HTx (filled circles) groups at different sampling times: before the operation; at the time of reperfusion; 30 minutes, 4 hours, and 24 hours after reperfusion; and 7 days after operation. Asterisks mark the sampling times when the values of a specified parameter differed significantly between the HTx $(n=24)$ and non-HTx $(n=30)$ groups (Mann-Whitney $\boldsymbol{U}$ test; ${ }^{* *} \boldsymbol{P}<.001 ;{ }^{* *} .001<\boldsymbol{P}<.01 ;{ }^{*} .01<\boldsymbol{P}<.05$ ). Crosses mark the sampling times when the values of a specified parameter differed significantly from the preoperative values (Wilcoxon matched paired test; $+++P<.001 ;++.001<P<.01 ;+.01<P<.05)$.

groups of patients. However, a relatively high variability of the parameters studied was observed in each group of patients during the perioperative and postoperative periods.
Patients in the HTx group were younger than those in the non-HTx group, but there is no evidence that the cytokine release is influenced by age.6,15 The duration of CPB and the 


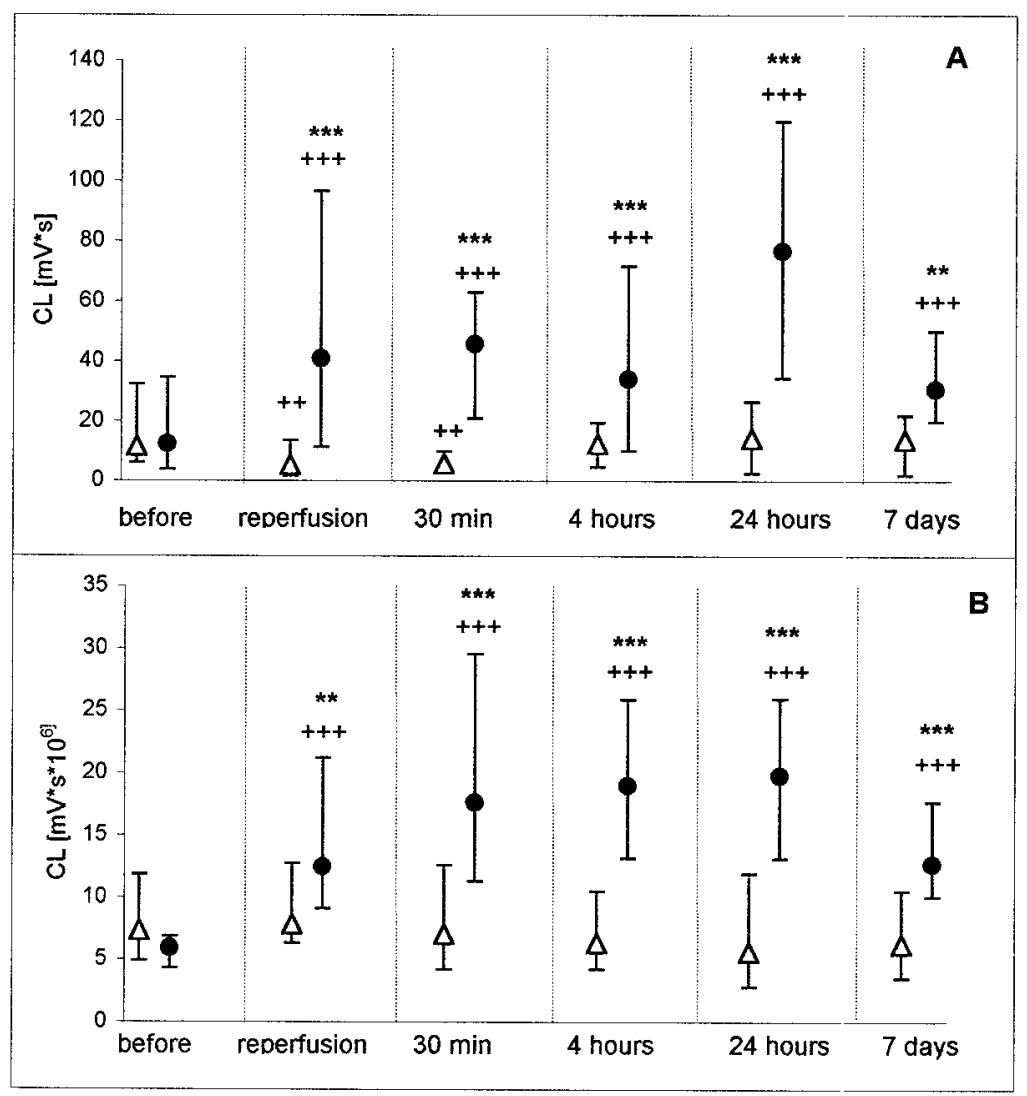

Figure 3. Time profiles of spontaneous (A) and OZP-activated (B) whole-blood chemiluminescence activities of phagocytes. The ordinate represents actual values in both the HTx (open triangles) and non-HTx (filled circles) groups at different sampling times: before the operation; at the time of reperfusion; 30 minutes, 4 hours, and 24 hours after reperfusion; and 7 days after operation. Asterisks mark the sampling times when the values of a specified parameter differed significantly between the HTx $(n=24)$ and non-HTx $(n=30)$ groups (Mann-Whitney $\boldsymbol{U}$ test; ${ }^{* * *} \boldsymbol{P}<.001 ;{ }^{* *} .001<\boldsymbol{P}<.01$. Crosses mark the sampling times when the values of a specified parameter differed significantly from the preoperative values (Wilcoxon matched paired test; $+++\boldsymbol{P}<.001 ;++.001<\boldsymbol{P}<$ .01).

TABLE 2. Time profiles of lipid peroxidation

\begin{tabular}{|c|c|c|c|c|c|c|c|}
\hline & \multirow[b]{2}{*}{ Patients } & \multicolumn{6}{|c|}{ Sampling times } \\
\hline & & Before & Reperfusion & $30 \mathrm{~min}$ & $4 \mathrm{~h}$ & $24 \mathrm{~h}$ & $7 \mathrm{~d}$ \\
\hline \multirow{2}{*}{$\begin{array}{l}\text { TBARS } \\
(\mu \mathrm{mol} / \mathrm{L})\end{array}$} & HTx & $6.1(3.7 ; 8.2)$ & $6.2(4.4 ; 8.3)$ & $8.0(6.6 ; 11.3)^{*}$ & $8.8(5.0 ; 11.1)^{*}$ & $6.8(4.4 ; 8.6)$ & $6.5(5.3 ; 8.1)$ \\
\hline & Non-HTx & $5.6(3.4 ; 8.2)$ & $6.2(4.2 ; 8.2)$ & $8.1(4.9 ; 11.4)^{*}$ & $8.4(5.1 ; 12.0)^{*}$ & $5.8(3.6 ; 8.1)$ & $6.0(3.9 ; 6.2)$ \\
\hline
\end{tabular}

Time profiles of the Thiobarbituric acid reactive substances plasma concentrations in both the HTx $(n=24)$ and non-HTx ( $n=30$ ) groups of patients at different sampling times: before the operation; at the time of reperfusion; 30 minutes, 4 hours, and 24 hours after reperfusion; and 7 days after the operation. Data are expressed as medians and lower and upper quartiles. Asterisks mark the sampling times when the values of a specified parameter differed significantly from the preoperative values (Wilcoxon matched paired test; ${ }^{*} .001 \leq P<.01$ ).

TBARS, Thiobarbituric acid reactive substances.

ischemic period (starting from aortic crossclamping on the donor heart in the HTx group) was longer in the HTx group than in the non-HTx group. Several authors have found a correlation between the ischemic period or the duration of
CPB and IL-6 or IL-8 concentrations. ${ }^{6,10,11,14}$ It suggests an important role of ischemia duration, as well as a role of the inflammatory consequences of longer periods in which blood is exposed to artificial materials or abnormal shear 
TABLE 3. Interrelationships between IL-6 and IL-8 at the time of reperfusion, 30 minutes after reperfusion, 4 hours after reperfusion, and 24 hours after reperfusion in the HTx and non-HTx groups

\begin{tabular}{|c|c|c|c|c|c|}
\hline & \multirow[b]{2}{*}{ Patients } & \multicolumn{4}{|c|}{ Sampling times } \\
\hline & & Reperfusion & $30 \mathrm{~min}$ & $4 \mathrm{~h}$ & $24 \mathrm{~h}$ \\
\hline IL-6 $\times$ IL-8 correlation & $\begin{array}{c}\text { HTx } \\
\text { Non-HTx }\end{array}$ & $\begin{array}{c}0.505 \\
P=.02 \\
0.510 \\
P=.004\end{array}$ & $\begin{array}{c}0.703 \\
P<.001 \\
0.618 \\
P<.001\end{array}$ & $\begin{array}{c}0.645 \\
P=.002 \\
0.642 \\
P<.001\end{array}$ & $\begin{array}{c}0.747 \\
P<.001 \\
0.548 \\
P=.001\end{array}$ \\
\hline
\end{tabular}

The values of the Spearman correlation coefficient with level of significance are shown for each sampling time.

forces. ${ }^{6,10,11}$ On the other hand, no correlation was found with IL-10.6,12,17 Some authors failed to find any correlation between the peak levels of IL- 6 or IL- 8 and CPB or aortic crossclamping duration..$^{3,9}$

The site of cytokine release during and after HTx and non-HTx is unclear. Fujiwara and associates ${ }^{3}$ suggested that $^{-}$ cytokines in serum did not originate from a specific location and that they could be released from leukocytes, macrophages, endothelial cells of systemic vasculature, or the parenchyma of tissue, such as muscles. On the other hand, the myocardium was suggested as an important source of IL-6 and IL-8 in CPB after reperfusion of the heart, ${ }^{8}$ and hypoperfused liver has been shown to be the main source of IL-10 during CPB. ${ }^{12}$ We found a positive correlation between the plasma levels of IL-6 and IL-8 in both groups of patients, which suggests an activation of their common source (monocytes-macrophages). Although the kinetics of IL-6, IL-8, and IL-10 releases measured in individual groups of patients were similar, no correlation with IL-10 was found. Frering and coworkers ${ }^{9}$ failed to observe any correlation between IL-6 and IL-8 levels in patients after CPB. On the other hand, Wan and associates ${ }^{12}$ found a positive correlation between IL-10 plasma levels and IL-8 and IL-6 in the non-HTx group.

In the present study a remarkable increase in lipid peroxidation measured on the basis of thiobarbituric acid reactive substances has been found in both groups of patients 4 and 24 hours after the operation. At the cellular level, the excessive oxidative stress causes damage of cell membrane lipids (lipid peroxidation), denaturation of proteins, breakdown of carbohydrates, and, consequently, lysis of endothelium and tissue injury. ${ }^{21}$ Our results are consistent with several previous studies in which oxidative stress and subsequent lipid peroxidation were demonstrated in patients undergoing cardiac operations involving CPB. ${ }^{16,21-24}$

In our study the significant increase in leukocyte numbers was observed in both groups of patients starting at the beginning of the operation. The higher leukocyte numbers in the HTx group were found at all sampling intervals, and this difference could result from the high doses of steroids in the HTx group. ${ }^{25}$ An inhibitory effect of methylprednisolone on neutrophil sequestration in the pulmonary vas- cular system has been shown by other authors. ${ }^{26}$ Activated polymorphonuclear leukocytes, which are sequestered into the pulmonary circulation and produce increased amounts of ROS, have been shown to be a causal factor of CPB's deleterious effects. $5,7,14 \mathrm{We}$ confirmed, in this study, the results from our previous study that the blood phagocyte ROS production is remarkably increased during reperfusion up to the seventh postoperative day in patients undergoing cardiac operations. ${ }^{4}$ The concurrent increase in neutrophil numbers, together with their boosted metabolic activity, contributed to the increased ROS production. Neutrophil priming with an increased production of superoxide during $\mathrm{CPB}$ has also been described by other authors. ${ }^{27,28}$ On the contrary, we have not found any increase in activated ROS production (spontaneous ROS production was even reduced) at an early phase of reperfusion in patients in the HTx group. It means that although neutrophil numbers were increased, their metabolic activity was suppressed. One of the possible explanations is the relative increase of not fully maturated neutrophils with lower potential of ROS production, whereas fully maturated neutrophils remained without a change at early times of reperfusion in patients in the HTx group. On the other hand, the relative counts of both forms of neutrophils were increased at these time intervals in the non-HTx group. Another possible explanation for the depressed activity of blood phagocytes in the HTx group could be the immunosuppressive therapy. There is a lack of studies describing the influence of immunosuppressive agents on the spontaneous and activated oxidative burst of phagocytes. However, we did not confirm a direct effect of immunosuppressive agents on the production of ROS by neutrophils in in vitro experiments in our previous study. ${ }^{29}$ Another possible explanation could be an influence of IL-10 on ROS production by blood phagocytes. There have been some reports showing inhibitory effects of IL-10 on the activity and ROS production by phagocytes, ${ }^{30}$ but contrary reports also exist. ${ }^{31} \mathrm{We}$ did not confirm a direct effect of IL-10 on the whole-blood production of ROS in in vitro experiments in concentrations up to 10 times higher than the average levels occurring during operations (unpublished data). The low chemiluminescence reactivity of phagocytes during HTx remains to be elucidated. 
In conclusion, we proved that the processes associated with HTx and non-HTx operations involving CPB are connected with increased oxidative stress and with increased production of both proinflammatory and anti-inflammatory cytokines. Concentrations of proinflammatory cytokines were on the same level in both groups, whereas the antiinflammatory IL-10 level was higher in the non-HTx group. We confirmed the contribution of circulating phagocytes to the increased oxidative stress in the non-HTx group. On the contrary, the activity of circulating phagocytes was depressed in patients in the HTx group. The observed differences between HTx and non-HTx operations could be caused mainly by the immunosuppressive therapy in HTx operations. However, other factors, such as a longer duration of ischemia in HTx, could be involved.

We thank Dr Blaha for his statistical guidance and analysis of the study.

\section{References}

1. Boyle EM, Pohlman TH, Johnson MC, Verrier ED. Endothelial cell injury in cardiovascular surgery: The Systemic inflammatory response. Ann Thorac Surg. 1997;62:1549-57.

2. Verrier ED, Boyle EMJ. Endothelial cell injury in cardiovascular surgery. Ann Thorac Surg. 1996;62:915-22.

3. Fujiwara T, Seo N, Murayama T, Hirata S, Kawahito K, Kawakami M. Transient rise in serum cytokines during coronary artery bypass graft surgery. Eur Cytokine Netw. 1997;8:61-6.

4. Lojek A, Černý J, Pillich J, Č́íž M, Kubícková D, Pavlícek V, et al. Human neutrophil mobilization during open heart surgery. Physiol Res. 1992;41:431-6.

5. Defraigne JO, Pincemail J, Larbuisson R, Blaffart F, Limet R. Cytokine release and neutrophil activation are not prevented by heparincoated circuits and aprotinin administration. Ann Thorac Surg. 2000; 69:1084-91.

6. Wan S, Marchant A, DeSmet JM, Antoine M, Zhang H, Vachiery JL, et al. Human cytokine responses to cardiac transplantation and coronary artery bypass grafting. J Thorac Cardiovasc Surg. 1996;111:46977.

7. Casey LC. Role of cytokines in the pathogenesis of cardiopulmonaryinduced multisystem organ failure. Ann Thorac Surg. 1993;56:S92-6.

8. Wan S, LeClerc JL, Vincent JL. Cytokine responses to cardiopulmonary bypass: lessons learned from cardiac transplantation. Ann Thorac Surg. 1997;63:269-76.

9. Frering B, Philip I, Dehoux M, Rolland C, Langlois JM, Desmonts JM. Circulating cytokines in patients undergoing normothermic cardiopulmonary bypass. $J$ Thorac Cardiovasc Surg. 1994;108:636-41.

10. Kawamura T, Inada K, Okada H, Okada K, Wakusawa R. Methylprednisolone inhibits increase of interleukin 8 and 6 during open heart surgery. Can J Anaesth. 1995;42:399-403.

11. Hennein HA, Ebba H, Rodriguez JL, Merrick SH, Keith FM, Bronstein $\mathrm{MH}$, et al. Relationship of the proinflammatory cytokines to myocardial ischemia and dysfunction after uncomplicated coronary revascularization. J Thorac Cardiovasc Surg. 1994;108:626-35.

12. Wan S, LeClerc JL, Schmartz D, Barvais L, Huynh CH, Deviere J, et al. Hepatic release of interleukin-10 during cardiopulmonary bypass in steroid-pretreated patients. Am Heart J. 1997;133:335-9.

13. Slavíková H, Lojek A, Hamar J, Dusková M, Kubala L, Vondrácek J, et al. Total antioxidant capacity of serum increased in early but not late period after intestinal ischemia in rats. Free Radic Biol Med. 1998; 25:9-18.

14. Finn A, Naik S, Klein N, Levinsky RJ, Strobel S, Elliott M. Interleukin-8 release and neutrophil degranulation after pediatric cardiopulmonary bypass. J Thorac Cardiovasc Surg. 1993;105:234-41.

15. Roth-Isigkeit A, Schwarzenberger J, von Borstel T, Gehring H, Ocklitz E, Wagner K, et al. Perioperative cytokine release during coronary artery bypass grafting in patients of different ages. Clin Exp Immunol. 1998;114:26-32.

16. Matata BM, Galinanes M. Cardiopulmonary bypass exacerbates oxidative stress but does not increase proinflammatory cytokine release in patients with diabetes compared with patients without diabetes: regulatory effects of exogenous nitric oxide. J Thorac Cardiovasc Surg. 2000;120:1-11.

17. Nathan N, Preux PM, Feiss P, Denizot Y. Plasma interleukin-4, interleukin-10, and interleukin-13 concentrations and complications after coronary artery bypass graft surgery. J Cardiothorac Vasc Anesth. 2000;14:156-60.

18. Wan S, DeSmet JM, Antoine M, Goldman M, Vincent JL, LeClerc JL. Steroid administration in heart and heart-lung transplantation: is the timing adequate? Ann Thorac Surg. 1996;61:674-8.

19. Wan S, LeClerc JL, Antoine M, DeSmet JM, Yim AP, Vincent JL. Heparin-coated circuits reduce myocardial injury in heart or heartlung transplantation: a prospective, randomized study. Ann Thorac Surg. 1999;68:1230-5.

20. Wan S, LeClerc JL, Schmartz D, Barvais L, Huynh CH, Deviere J, et al. Hepatic release of interleukin-10 during cardiopulmonary bypass in steroid-pretreated patients. Am Heart J. 1997;133:335-9.

21. Starkopf J, Tamme K, Zilmer M, Talvik R, Samarutel J. The evidence of oxidative stress in cardiac surgery and septic patients: a comparative study. Clin Chim Acta. 1997;262:77-88.

22. Toivonen HJ, Ahotupa M. Free radical reaction products and antioxidant capacity in arterial plasma during coronary artery bypass grafting. J Thorac Cardiovasc Surg. 1994;108:140-7.

23. Coghlan JG, Flitter WD, Clutton SM, Ilsley CD, Rees A, Slater TF. Lipid peroxidation and changes in vitamin E levels during coronary artery bypass grafting. J Thorac Cardiovasc Surg. 1993;106:268-74.

24. Davies SW, Duffy JP, Wickens DG, Underwood SM, Hill A, Alladine MF, et al. Time-course of free radical activity during coronary artery operations with cardiopulmonary bypass. J Thorac Cardiovasc Surg. 1993;105:979-87.

25. Claman HN. Glucocorticosteroids I: anti-inflammatory mechanisms. Hosp Pract. 1983;18:123-6.

26. Dernek S, Tunerir B, Sevin B, Aslan R, Uyguc O, Kural T. The effects of methylprednisolone on complement, immunoglobulins and pulmonary neutrophil sequestration during cardiopulmonary bypass. Cardiovasc Surg. 1999;7:414-8.

27. Partrick DA, Moore EE, Fullerton DA, Barnett CC, Meldrum DR, Silliman CC. Cardiopulmonary bypass renders patients at risk for multiple organ failure via early neutrophil priming and late neutrophil disability. J Surg Res. 1999;86:42-9.

28. Kawahito K, Kobayashi E, Ohmori M, Harada K, Kitoh Y, Fujimura A, et al. Enhanced responsiveness of circulatory neutrophils after cardiopulmonary bypass: increased aggregability and superoxide producing capacity. Artif Organs. 2000;24:37-42.

29. Duskova M, Dusek L, Ciz M, Lojek A, Slavikova H. The influence of some immunosuppressive drugs on the metabolic activity of human phagocytes and lymphocytes in vitro. Int J Immunopathol Pharmacol. 1998;11:155-162.

30. Capsoni F, Minonzio F, Ongari AM, Carbonelli V, Galli A, Zanussi C. Interleukin-10 down-regulates oxidative metabolism and antibodydependent cellular cytotoxicity of human neutrophils. Scand J Immunol. 1997;45:269-75.

31. Réglier-Poupet H, Hakim J, Gougerot-Pocidalo MA, Elbim C. Absence of regulation of human polymorphonuclear oxidative burst by interleukin-10, interleukin-4, interleukin-13 and transforming growth factor-beta in whole blood. Eur Cytokine Netw. 1998;9:633-8. 